\title{
Two-Dimensional Nuclear Magnetic Resonance Spectra of Cellulose and Cellulose Triacetate
}

\author{
Keisuke KowsaKa, Kunihiko OKaJIMA, and Kenji KamidE* \\ Fundamental Research Laboratory of Fibers and Fiber-Forming Polymers, \\ Asahi Chemical Industry Co., Ltd., \\ 11-7 Hacchonawate, Takatsuki, Osaka 569, Japan
}

(Received April 4, 1988)

\begin{abstract}
An attempt was made to give a full assignment, using only NMR information, to all peaks in ${ }^{1} \mathrm{H}$ and ${ }^{13} \mathrm{C}$ NMR spectra for systems of cellulose in $2.5 \mathrm{~N} \mathrm{NaOD} / \mathrm{D}_{2} \mathrm{O}$ and of cellulose triacetate (CTA, total degree of substitution 2.92) in deuterated trichloromethane (TCM- $d$ ), and in deuterated dimethylsulfoxide (DMSO- $d_{6}$ ). For this purpose two-dimensional (2D) homonuclear ${ }^{1} \mathrm{H}$ shift correlation spectroscopy (COSY), heteronuclear ${ }^{1} \mathrm{H}^{-1}{ }^{13} \mathrm{C}$ shift correlation spectroscopy (C-H COSY), and long-range heteronuclear ${ }^{1} \mathrm{H}-{ }^{13} \mathrm{C}$ shift correlation spectroscopy (long-range $\mathrm{C}-\mathrm{H}$ COSY) were applied to the above systems. By COSY ${ }^{1} \mathrm{H}$ peaks of cellulose/aq. alkali solution were assigned, from lower magnetic field, to $\mathrm{H}_{1}, \mathrm{H}_{6}, \mathrm{H}_{6}{ }^{\prime},\left(\mathrm{H}_{3}+\mathrm{H}_{4}+\mathrm{H}_{5}\right)$, and $\mathrm{H}_{2}$ protons, respectively. Here, two unequivalent $\mathrm{H}_{6}$ peaks heavily overlapped in the one-dimensional spectrum were observed very separately in $2 \mathrm{D}$ spectrum. By $\mathrm{C}-\mathrm{H}$ COSY ${ }^{13} \mathrm{C}$ peaks of cellulose were assigned, from lower magnetic field, to $\mathrm{C}_{1},\left(\mathrm{C}_{3}, \mathrm{C}_{4}, \mathrm{C}_{5}\right), \mathrm{C}_{2}$, and $\mathrm{C}_{6}$ carbons, respectively. $\mathrm{C}_{3}, \mathrm{C}_{4}$, and $\mathrm{C}_{5}$ carbon peaks were unable to be assigned separately, due to mutual and heavy overlapping of $\mathrm{H}_{3}, \mathrm{H}_{4}$, and $\mathrm{H}_{5}$ peaks. For cellulose triacetate, through use of COSY and C-H COSY all peaks in the region of glucopyranose backbone in ${ }^{1} \mathrm{H}$ and ${ }^{13} \mathrm{C}$ NMR wre able to be successfully and completely assigned. Long-range $\mathrm{C}-\mathrm{H}$ COSY confirmed definitely the existence of the close correlationships between acetyl methyl proton and carbonyl carbon at the different carbon positions of CTA, which showed again the validity of the previous assignment with respect to carbonyl carbons (i.e., $\mathrm{C}_{6}, \mathrm{C}_{3}$, and $\mathrm{C}_{2}$ carbons from lower magnetic field).

KEY WORDS Cellulose / Cellulose Acetate / Cellulose Triacetate / ${ }^{13} \mathrm{C}$ NMR / ${ }^{1} \mathrm{H}$ NMR / Two-Dimensional NMR / Correlation Spectroscopy / Long-Range Heteronuclear Correlation Spectroscopy /
\end{abstract}

Recently numerous studies have been published on the high resolution NMR spectra of solutions of cellulose and its derivatives. NMR spectra of cellulose were utilized widely as a method for elucidating the dissolved state of solutes in solvents (i.e., interaction between solutes and solvents) and those of cellulose derivatives were employed for analysis of the average degree of substitution for each three hydroxyl groups $\left\langle\mathrm{f}_{k}\right\rangle(k=2,3,6)$ in the glucopyranose unit: For example, Kamide et al. ${ }^{1}$ showed, from ${ }^{1} \mathrm{H}$ NMR spectra of cel- lulose in dimethylformamide/chloral/pyridine mixture, that cellulose dissolved in the form of cellulose trichlorate (CTC) in the solution. Gagnaire and his coworkers ${ }^{2}$ speculated the dissolved state of cellulose in $N$ methylmorpholine- $N$-Oxide/dimethylsulfoxide (DMSO), methylamine/DMSO, hydrazine/ DMSO, and paraformaldehyde/DMSO by comparing the ${ }^{13} \mathrm{C}$ chemical shifts in these solutions. Kamide and his collaborators ${ }^{3}$ showed that a physically treated cellulose, whose intramolecular hydrogen bondings were de-

\footnotetext{
* To whom all correspondence should be addressed.
} 
stroyed to some extent, was completely soluble in aq sodium hydroxide at $0-10^{\circ} \mathrm{C}$ and measured first ${ }^{13} \mathrm{C}$ NMR spectra of cellulose (prepared thus) $/ \mathrm{NaOD} / \mathrm{D}_{2} \mathrm{O}$ solution.

From systematic analysis on ${ }^{1} \mathrm{H}$ and ${ }^{13} \mathrm{C}$ NMR spectra of sodium cellulose sulfate, ${ }^{4}$ cellulose acetate (CA), ${ }^{5-7}$ sodium carboxymethylcellulose ${ }^{8}$ sodium cellulose xanthate (CX), ${ }^{9}$ carboxyethylcarbamoylethylcellulose ${ }^{10}$ and cyanoethylcellulose, ${ }^{11}$ Kamide, Okajima, and their coworkers elucidated $\left\langle\mathrm{f}_{k}\right\rangle(k=2,3$, $6)$, correlation $\left\langle\mathrm{f}_{k}\right\rangle$ with some physical and physilogical properties. $\mathrm{Wu},{ }^{12}$ Clark and Stephenson, ${ }^{13}$ and Miyamoto et al. $^{14}$ estimated, from NMR spectra, $\left\langle\mathrm{f}_{\boldsymbol{k}}\right\rangle$ of cellulose nitrate and CA.

In the above studies, assignment of NMR peaks was exclusively prerequisite in order to employ the NMR method for $\left\langle\mathrm{f}_{k}\right\rangle$ determination. It is extremely difficult to get high resolution ${ }^{1} \mathrm{H}$ NMR spectra for cellulose and its derivatives with high degree of polymerization (DP), enabling us to obtain information on vicinal proton coupling, even if employing selective homonuclear decoupling. Peak assignment of ${ }^{13} \mathrm{C}$ NMR spectrum is generally more difficult than that of ${ }^{1} \mathrm{H}$ NMR, needing rather considerably complicated, and skillful techniques. For example, by applying the selective heteronuclear spin decoupling technique in measurement of ${ }^{13} \mathrm{C}$ NMR of cellulose oligomer with DP $=10$ in DMSO, and also by taking into account an isotope effect of deuterated compounds, Gagnaire et al. ${ }^{2}$ assigned, from lower magnetic field, the peaks of cellulose oligomer, to $\mathrm{C}_{1}, \mathrm{C}_{4}, \mathrm{C}_{5}, \mathrm{C}_{3}, \mathrm{C}_{2}$, and $\mathrm{C}_{6}$ carbons, respectively. Kowsaka and his coworkers, ${ }^{6}$ assigned, by applying low-power selective spin decoupling technique, the peaks of carbonyl carbon of acetyl group directly combined with $\mathrm{C}_{2}, \mathrm{C}_{3}$, and $\mathrm{C}_{6}$ positions of $\mathrm{CA}$ and assigned also, ${ }^{9}$ with the help of distortionless enhancement by polarization transfer (DEPT) technique, $\mathrm{C}_{6}$ peak of CX. In the literature, except for these described here, the peak assignments were not carried out by only the NMR method, but by an indirect method including a comparison of the peak intensity ratio in NMR spectrum of the sample with $\left\langle\mathrm{f}_{k}\right\rangle$, determined in advance by non-NMR method or from analogy of the peak assignment of small molecular weight model compounds or of other derivatives.

The assignment given by Gagnaire et al. ${ }^{2}$ for cellulose can be considered reasonable in DMSO- $d_{6}$; however, mention should be made of the assignment of peaks in other solvents: it could not always be done, by referring to their assignment straightly, because $\mathrm{C}_{5}, \mathrm{C}_{3}$, and $\mathrm{C}_{2}$ peaks of cellulose oligomer in DMSO- $d_{6}$ were located very close to each other and the order of the peak positions may possibly to change in other solvents. In addition, note that the positions of the ring carbon peaks are significantly influenced by substitution of hydroxyl groups in cellulose derivatives, for which the assignment for cellulose by Gagnaire et al. cannot be straightforwardly applied as it is and the methods proposed hithertofor in analysis of NMR spectra of cellulose derivatives are without exception too elaborate and timeconsuming and additionally they are not sufficiently accurate.

Very recent advances in two-dimensional (2D) NMR technique allow us relatively easily to perform an absolute (in other word, by pure NMR method) assignment of ${ }^{1} \mathrm{H}$ and ${ }^{13} \mathrm{C}$ NMR peaks. Narden and Vincendon ${ }^{15}$ attempted, using $2 \mathrm{D}$ homonuclear ${ }^{1} \mathrm{H}$ shift correlation spectrum and $2 \mathrm{D}$ heteronuclear ${ }^{13} \mathrm{C}$ ${ }^{1} \mathrm{H}$ shift correlation spectrum (and for the latter measurement, using $5 \%{ }^{13} \mathrm{C}$ enriched cellulose), to assign ${ }^{1} \mathrm{H}$ and ${ }^{13} \mathrm{C}$ peaks of cellulose in deuterated dimethylacetamide (DMAC- $\left.d_{9}\right)$ /lithium chloride mixture, but unfortunately, they failed to distinguish the $C_{3}$ peak from $\mathrm{C}_{5}$ peaks.

This article attempts to privide a much better and more reliable assignment, using $2 \mathrm{D}$ NMR alone, of peaks in ${ }^{1} \mathrm{H}$ and ${ }^{13} \mathrm{C}$ NMR spectra of cellulose in $\mathrm{NaOD} / \mathrm{D}_{2} \mathrm{O}$ solution and cellulose triacetate (total degree of sub- 
stitution $\langle\langle\mathrm{F}\rangle=2.92)$ in trichloromethane-d (TCM- $d$ ) and in DMSO- $d_{6}$.

\section{EXPERIMENTAL}

\section{Samples}

An alkali-soluble, regenerated cellulose with the viscosity-average molecular weight $\bar{M}_{v}=$ $1.38 \times 10^{4}$, as measured by solution viscosity in cadoxen solution at $25^{\circ} \mathrm{C}$ according to MarkHouwink-Sakurada equation by Brown and Wikström, ${ }^{16}$ was prepared by the previously reported method. ${ }^{1} \mathrm{~A} 40 \mathrm{wt} \% \mathrm{NaOD} / \mathrm{D}_{2} \mathrm{O}$ solution $(99 \%$ deuterated; manufactured by Merck, DBR) was diluted with $99.8 \%$ deuterated $\mathrm{D}_{2} \mathrm{O}$ (Merck, Canada) to prepare at $2.5 \mathrm{~N} \mathrm{NaOD} / \mathrm{D}_{2} \mathrm{O}$ solution, into which a cellulose sample was dissolved carefully at $4{ }^{\circ} \mathrm{C}$ and $2 \mathrm{wt} \%$ and $5 \mathrm{wt} \%$ solutions of cellulose were prepared for further measurements of ${ }^{1} \mathrm{H}$ and ${ }^{13} \mathrm{C}$ NMR, respectively.

An whole cellulose triacetate (CTA) with the weight-average molecular weight $\bar{M}_{w}=2.32 \times$ $10^{5}$ (by light scattering in DMAC) and $\langle\mathrm{F}\rangle=2.92$ was dissolved in $99.8 \%$ deuterated TCM- $d$ at $40^{\circ} \mathrm{C}$ and in $99.9 \%$ deuterated DMSO- $d_{6}$ (Merck, Canada) at $80^{\circ} \mathrm{C}$ to give $8 \mathrm{wt} \%$ solutions, used for NMR measurements.

\section{NMR Measurement}

A JEOL FT-NMR spectrometer JNM-FX$200(\mathrm{C} / \mathrm{H}, 10 \mathrm{~mm} \phi$ probe $)$ was used. ${ }^{1} \mathrm{H}$ and ${ }^{13} \mathrm{C}$ resonance frequencies were 199.5 and
$50.18 \mathrm{MHz}$, respectively.

Homonuclear ${ }^{1} \mathrm{H}$ shift correlation spectroscopy $(\mathrm{COSY})^{17}$ experiments were carried out using the pulse sequence as shown in Figure 1(a). The trapezoidal window was employed for Fourier-transform. The detailed measuring conditions for each sample are collected in Table I. For cellulose/ $\mathrm{NaOD} / \mathrm{D}_{2} \mathrm{O}$ system, homogate decoupling was simultaneously employed in order to reduce signals originating from remained protons in the solvent mixture.

The heteronuclear ${ }^{13} \mathrm{C}-{ }^{1} \mathrm{H}$ shift correlation spectrum $(\mathrm{C}-\mathrm{H} \text { COSY })^{17}$ was recorded using the pulse sequences shown in Figure 1(b). The mixing time $\Delta$ was set up to be $2.0 \mathrm{~ms}$ $\left(=1 /\left(4 J_{\mathrm{C}-\mathrm{H}}\right)\right)$, where $J_{\mathrm{C}-\mathrm{H}}$ is the coupling constant between $\mathrm{C}$ and $\mathrm{H}$ nuclei. For CTA longrange $\mathrm{C}-\mathrm{H}$ COSY was concurrently employed to determine correlations between carbonyl carbon and acetyl methyl protons. In this case, $\Delta$ was first taken as $166 \mathrm{~ms}\left(=1 /\left(4 J_{\mathrm{C}-\mathrm{C}-\mathrm{H}}\right)\right.$,
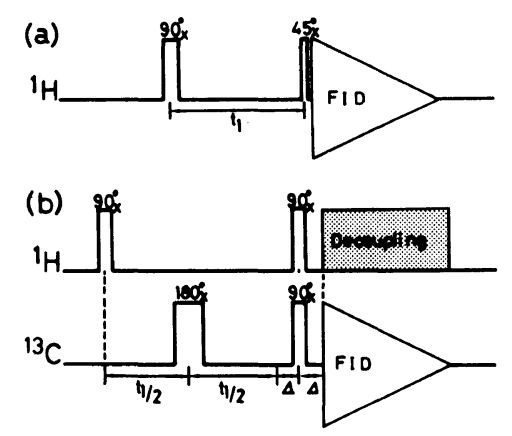

Figure 1. Pulse sequences used for 2D NMR measurements: a, proton COSY; b, C-H COSY.

Table I. Experimental conditions employed for COSY measurements

\begin{tabular}{|c|c|c|c|c|c|}
\hline \multirow{2}{*}{ Polymer/solvent } & \multirow{2}{*}{$\frac{\text { Temp }}{{ }^{\circ} \mathrm{C}}$} & \multirow{2}{*}{$\begin{array}{c}90^{\circ} \text { pulse } \\
\text { width } \\
\mu \mathrm{s}\end{array}$} & \multirow{2}{*}{$\begin{array}{c}\text { Spectral } \\
\text { width }\end{array}$} & \multirow[t]{2}{*}{ Data matrix ${ }^{a}$} & \multirow{2}{*}{$\frac{\text { Accumulation }}{\text { times }}$} \\
\hline & & & & & \\
\hline Cellulose $/ \mathrm{NaOD}^{\mathrm{b}}$ & 40 & 27.0 & 625 & $\begin{array}{c}512 \times 177 \\
(1024 \times 256)\end{array}$ & 128 \\
\hline CTA/TCM- $d$ & 40 & 14.0 & 1666 & $1024 \times 512$ & 16 \\
\hline CTA/DMSO- $d_{6}$ & 90 & 14.4 & 1000 & $1024 \times 256$ & 128 \\
\hline
\end{tabular}

\footnotetext{
a Number in parenthesis indicates expanded matrix by zero-filling.

b Homogate decoupled.
} 
Table II. Experimental conditions for C-H COSY measurements

\begin{tabular}{|c|c|c|c|c|c|c|c|c|}
\hline \multirow[t]{2}{*}{ Polymer/solvent } & \multirow{2}{*}{$\frac{\text { Temp }}{{ }^{\circ} \mathrm{C}}$} & \multirow{2}{*}{$\begin{array}{c}{ }^{1} \mathrm{H} 90^{\circ} \\
\text { pulse } \\
\text { width }\end{array}$} & \multirow{2}{*}{$\begin{array}{c}{ }^{13} \mathrm{C} 90^{\circ} \\
\text { pulse } \\
\text { width }\end{array}$} & \multirow{2}{*}{$\begin{array}{c}\begin{array}{c}{ }^{1} \mathrm{H} \\
\text { spectral } \\
\text { width }\end{array} \\
\frac{\mathrm{Hz}}{}\end{array}$} & \multirow{2}{*}{ 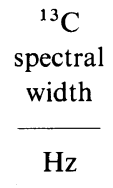 } & \multirow{2}{*}{$\frac{\Delta}{\mathrm{ms}}$} & \multirow{2}{*}{$\frac{\begin{array}{c}\text { Data } \\
\text { matrix }\end{array}}{{ }^{13} \mathrm{C} \times{ }^{1} \mathrm{H}}$} & \multirow{2}{*}{$\begin{array}{l}\text { Accumu- } \\
\text { lation }\end{array}$} \\
\hline & & & & & & & & \\
\hline Cellulose/NaOD & 20 & 27.0 & 23.0 & 625 & 4000 & 2.0 & $\begin{array}{c}1024 \times 99 \\
(2048 \times 128)\end{array}$ & 2048 \\
\hline CTA/TMC- $d$ & 40 & 14.0 & 13.0 & 1666 & 6002 & 2.0 & $\begin{array}{c}2048 \times 94 \\
(2048 \times 128)\end{array}$ & 2048 \\
\hline CTA/TCM- $d$ & 40 & 14.0 & 13.0 & 250 & 250 & 20.0 & $\begin{array}{c}512 \times 128 \\
(1024 \times 256)\end{array}$ & 512 \\
\hline CTA/DMSO- $d_{6}$ & 90 & 14.0 & 13.0 & 1250 & 6002 & 2.0 & $\begin{array}{c}2048 \times 96 \\
(2048 \times 128)\end{array}$ & 512 \\
\hline CTA/DMSO- $d_{6}$ & 90 & 14.0 & 13.0 & 1000 & 500 & 30.0 & $\begin{array}{c}512 \times 188 \\
(1024 \times 256)\end{array}$ & 128 \\
\hline
\end{tabular}

a Number in parenthesis indicates expanded matrix by zero-filling.

$J_{\mathrm{C}-\mathrm{C}-\mathrm{H}}$ is the long-range $\mathrm{C}-\mathrm{H}$ coupling constant), but the signal was extremely weak to obtain a sufficiently large signal noise $(\mathrm{S} / \mathrm{N})$ ratio due to the remarkably short $(<50 \mathrm{~ms})$ spin-spin relaxation time $T_{2}$ and then we chose the adequate value of $\Delta$, determined by trialand-error method under the conditions of $\Delta<50 \mathrm{~ms}$. The exponential and trapezoidal windows were employed for $t_{2}\left({ }^{13} \mathrm{C}\right)$ and $t_{1}\left({ }^{1} \mathrm{H}\right)$, respectively. The detailed measuring conditions are summerized for each polymersolvent system in Table II.

2D spectra were demonstrated by a stacked plot and plane figures were constructed by taking into the consideration the onedimensional spectra of cross sections. ${ }^{13} \mathrm{C}$ and ${ }^{1} \mathrm{H}$ chemical shifts for cellulose and CTA were determined from one-dimensional spectra, independently measured, by an internal reference of sodium trimethylsilylpropionate- $d_{4}$ (TSP $(=0 \mathrm{ppm}))$ and tetramethylsilane (TMS $(=0 \mathrm{ppm}))$, respectively.

\section{RESULTS AND DISCUSSION}

Figure 2(a) and (b) show ${ }^{1} \mathrm{H}$ (homogate decoupled) and ${ }^{13} \mathrm{C}$ 1D NMR spectra of cellulose $/ \mathrm{NaOD} / \mathrm{D}_{2} \mathrm{O}$ systems. Figure 3 shows

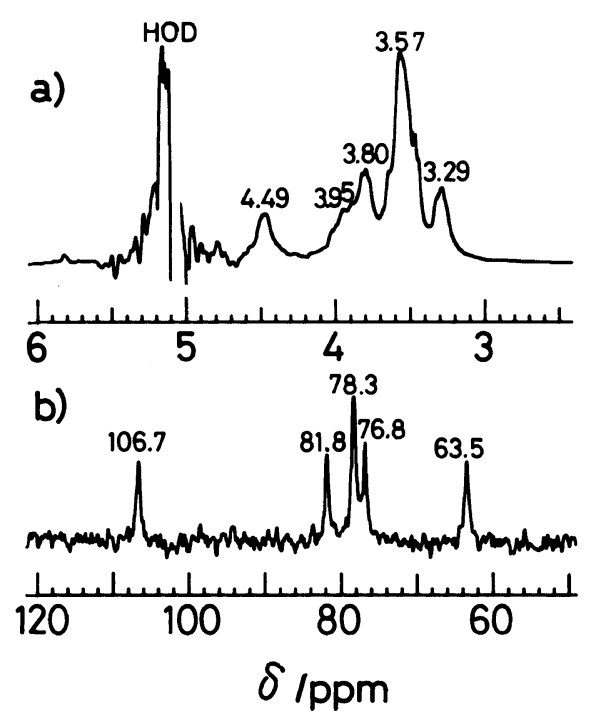

Figure 2. 1D NMR spectra of cellulose $/ \mathrm{NaOH} / \mathrm{D}_{2} \mathrm{O}$ system: a, ${ }^{1} \mathrm{H}$ NMR (homogate decoupled); b, ${ }^{13} \mathrm{C}$ NMR (gated decoupled).

COSY (stacked plot, cellulose region) of the same system. Evidently, a peak at $3.57 \mathrm{ppm}$ is relatively higher in intensity than the other peaks, and suggesting plural proton peaks. Despite homogate decoupling, a large peak due to residual proton in the solvent was observed. A rapid exchange in proton of the hydroxyl group in glucopyranose ring with 


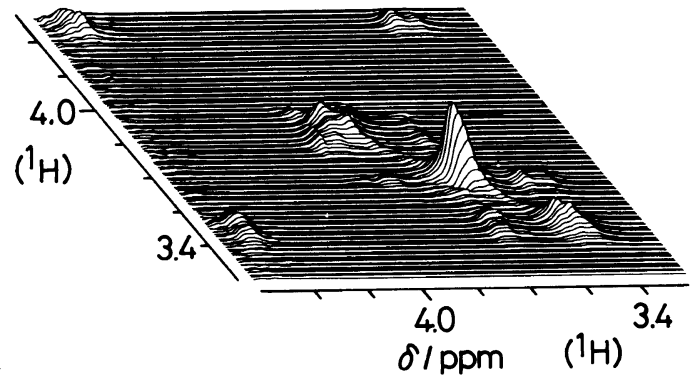

Figure 3. Stacked plot for COSY spectrum of cellulose $/ \mathrm{NaOD} / \mathrm{D}_{2} \mathrm{O}$ (cellulose region).

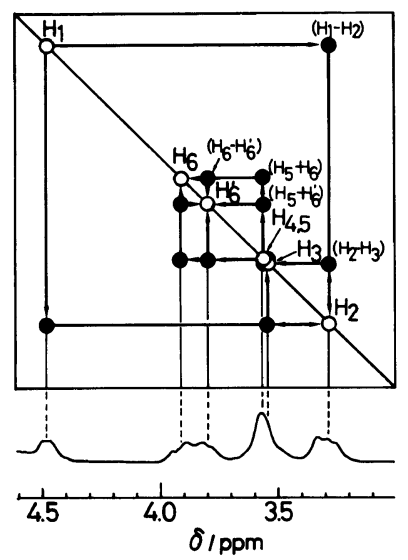

Figure 4. Schematic COSY spectrum of cellulose/ $\mathrm{NaOD} / \mathrm{D}_{2} \mathrm{O}$ : Filled and unfilled marks denote crosspeaks and dia-peaks, respectively. In the figure, correlations between protons are shown in parenthesis.

residual proton in the solvent does not enable us to distinguish, in ${ }^{1} \mathrm{H}$ NMR spectra, the hydroxyl proton peak from the residual proton peak. Over the $3.8-4.0 \mathrm{ppm}$ region of the $1 \mathrm{D}$ spectrum, a broad peak is observed. The existence of cross-peak in COSY indicates more explicitly that this is a triplet, consisting of closely overlapping two peaks (3.80 and 3.95 ppm), both combined with a single $3.57 \mathrm{ppm}$ peak.

Figure 4 shows a schematic 2D spectrum of the cellulose $/ \mathrm{NaOD} / \mathrm{D}_{2} \mathrm{O}$ system, constructed from Figure 3 and its cross section. In the figure, the projection of spectra in Figure 3 on the two axis is also illustrated. Diapeaks (open circle) in 2D spectrum correspond to each

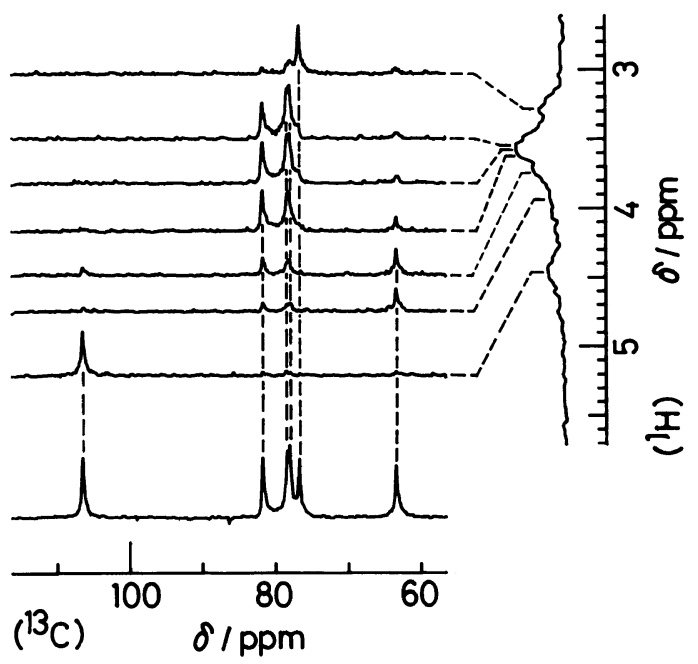

Figure 5. Cross-sections of $\mathrm{C}-\mathrm{H}$ COSY spectrum of cellulose $/ \mathrm{NaOD} / \mathrm{D}_{2} \mathrm{O}$.

peak in the 1D spectrum and cross-peaks (filled circle) reveal the existence of coupling between neighbouring protons. For a doublet peak at $4.5 \mathrm{ppm}$ in 1D-spectrum only single cross-peak is observed in 2D-spectrum. This means clearly that the peak has only a single vicinal coupling proton: The proton is obviously a proton at $\mathrm{C}_{1}$ position $\left(\mathrm{H}_{1}\right)$. Accordingly, a triplet proton peak reveals vicinal coupling with the $\mathrm{H}_{1}$ peak at $3.29 \mathrm{ppm}$ and is assigned to $\mathrm{H}_{2}$. In a similar manner, a peak at $3.57 \mathrm{ppm}$, coupled with $\mathrm{H}_{2}$ peak is assigned to $\mathrm{H}_{3}$, but, as described previously, this peak is heavily overlapped by other peaks and is not separable. Peaks at 3.80 and 3.95 ppm couple to each other and also both couple with a $3.57 \mathrm{ppm}$ peak, strongly suggesting that the two former are non-equivalent $\mathrm{H}_{6}$ proton peaks and the latter peak is assigned to $\mathrm{H}_{5}$ proton. Then, it can be considered that a notyet assigned $\mathrm{H}_{4}$ peak overlaps with a $\mathrm{H}_{5}$ peak (3.57 ppm).

Figure 5 shows the projection of $\mathrm{C}-\mathrm{H}$ COSY of cellulose $/ \mathrm{NaOD} / \mathrm{D}_{2} \mathrm{O}$ system on each axis, and its cross section spectra at ${ }^{1} \mathrm{H}$ peak position. A schematic $2 \mathrm{D}$ spectrum was drawn from the figure and is shown in Figure 


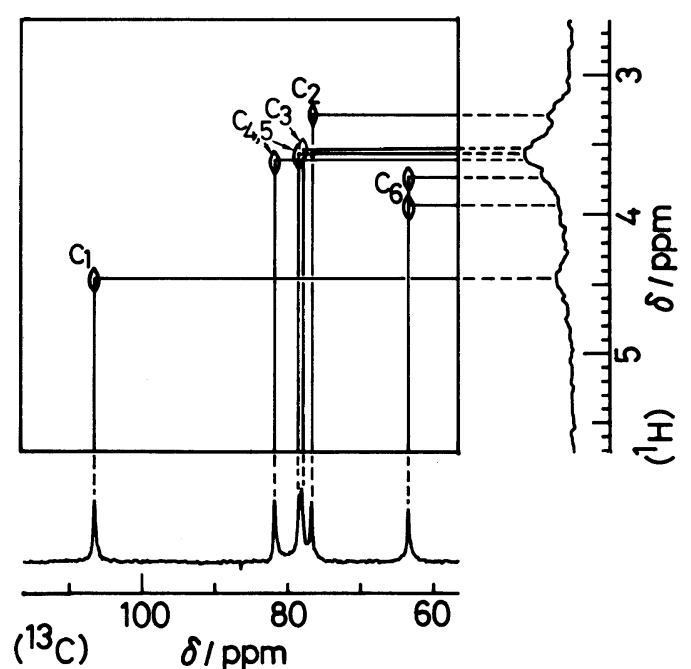

Figure 6. Schematic C-H COSY spectrum of cellulose/ $\mathrm{NaOD} / \mathrm{D}_{2} \mathrm{O}$.

6. Horizontal and longitudinal axes are ${ }^{13} \mathrm{C}$ and ${ }^{1} \mathrm{H}$ chemical shifts, respectively and projections on each axis are also shown. Peaks on 2D-spectrum clearly show $\mathrm{C}-\mathrm{H}$ scalarcoupling, indicating the correlation between ${ }^{13} \mathrm{C}-{ }^{1} \mathrm{H}$ peaks. Then, based on the assignment on proton peaks, determined in Figure 4, three peaks at $106.7,76.8$ and $63.5 \mathrm{ppm}$ in ${ }^{13} \mathrm{C}$ NMR spectrum are exactly assigned to the $\mathrm{C}_{1}, \mathrm{C}_{2}$, and $\mathrm{C}_{6}$ carbon peaks, respectively. A peak at $81.8 \mathrm{ppm}$ and a doublet peak at $78.3 \mathrm{ppm}$ (in total three carbon peaks) cannot be assigned explicitly due to the heavy overlapping of the proton peaks at $3.57 \mathrm{ppm}$ which are directly correlated with the above three carbon peaks. The above assignment carried out here for ${ }^{13} \mathrm{C}$ peak is, as far as $\mathrm{C}_{1}, \mathrm{C}_{2}$, and $\mathrm{C}_{6}$ carbon peaks are concerned, in good coincidence with those by Gagnaire et l. $^{2}$ for cellulose oligomer/ DMSO- $d_{6}$ system and by Nardin and Vincendon $^{15}$ for cellulose/DMAC/LiCl system.

Figure 7 (a) shows the ${ }^{1} \mathrm{H}$ 1D-NMR spectrum of CTA/TCM- $d$ system. In the spectrum, proton peaks due to the glucopyranose skeleton are observed in 3.5-5.2 ppm, and three acetyl methyl proton peaks are observed at 2.11, 1.99, and 1.95 ppm. Figure 7(b), (c), and (d)

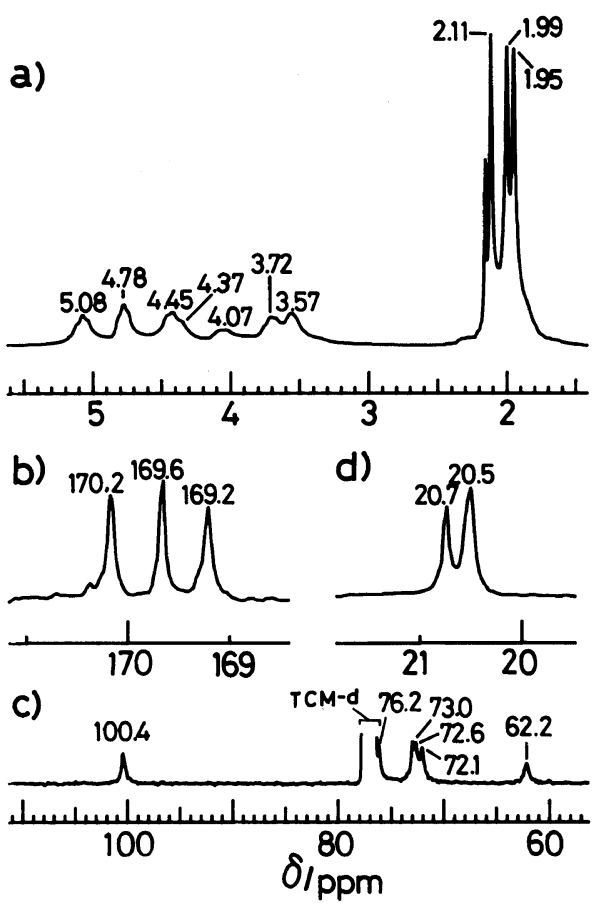

Figure 7. ID NMR spectra of CTA/TCM- $d$ system: a, ${ }^{1} \mathrm{H}$ NMR; b, c, d, ${ }^{1} \mathrm{H}$ noise decoupled ${ }^{13} \mathrm{C}$ NMR; b, carbonyl carbon region; c, glucopyranose carbon region; $\mathrm{d}$, acetyl methyl carbon region.

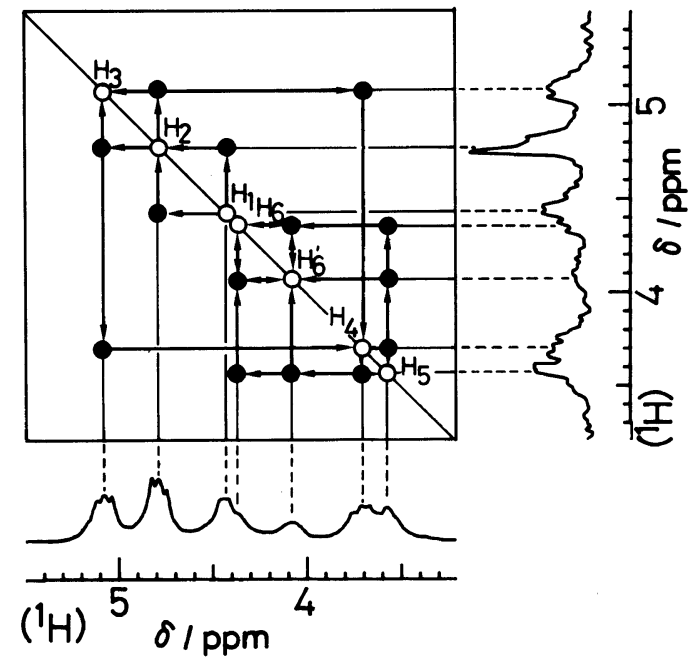

Figure 8. Schematic COSY spectrum of CTA/TCM- $d$ (glucopyranose region): Filled and unfilled marks denote cross-peaks and dia-peaks, respectively. 


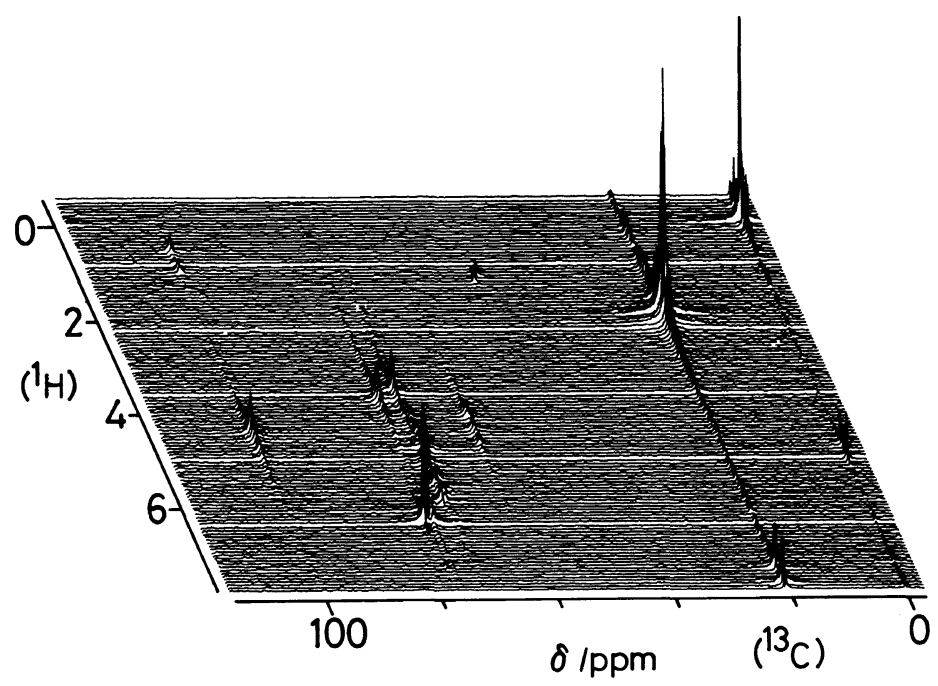

Figure 9. Stacked plot for C-H COSY spectrum of CTA/TCM-d.

show acetyl, glucopyranose and acetyl methyl regions of ${ }^{13} \mathrm{C} 1 \mathrm{D}-\mathrm{NMR}$ spectrum of the CTA/TCM- $d$ system.

Figure 8 shows a schematic COSY 2Dspectrum of the glucopyranose skeleton region of the CTA/TCM- $d$ system, constructed from a stacked plot and cross sections of COSY spectrum, as well as its projection. A peak at $4.45 \mathrm{ppm}$ reveals vicinal coupling with a peak at $4.78 \mathrm{ppm}$ alone, being assigned to $\mathrm{H}_{1}$. In the same way as in the case of the cellulose/ $\mathrm{NaOD} / \mathrm{D}_{2} \mathrm{O}$ system, we can assign $\mathrm{H}_{2}$ and $\mathrm{H}_{3}$. In addition, in the case of CTA $\mathrm{H}_{3}, \mathrm{H}_{4}$, and $\mathrm{H}_{5}$ peaks are observed separately and then each peak is able to be assigned completely. As result, all peaks are assigned, from lower magnetic field, to $\mathrm{H}_{3}, \mathrm{H}_{2}, \mathrm{H}_{1}, \mathrm{H}_{6}, \mathrm{H}_{6}{ }^{\prime}, \mathrm{H}_{4}$, and $\mathrm{H}_{5}$, respectively (here $\mathrm{H}_{6}{ }^{\prime}$ is the other half of unsymmetric $\mathrm{H}_{6}$ peaks). This assignment is denoted on dia-peaks (open circle) in Figure 8. Nute that in 1D-spectrum (Figure 7(a)) a $\mathrm{H}_{6}{ }^{\prime}$ peak heavily overlaps a $\mathrm{H}_{1}$ peak so that peak separation is impossible, but such a separation becomes very easy with the help of a crosspeak in the $2 \mathrm{D}$-spectrum.

Figure 9 shows the glucopyranose region and acetyl region of C-H COSY (stacked plot)

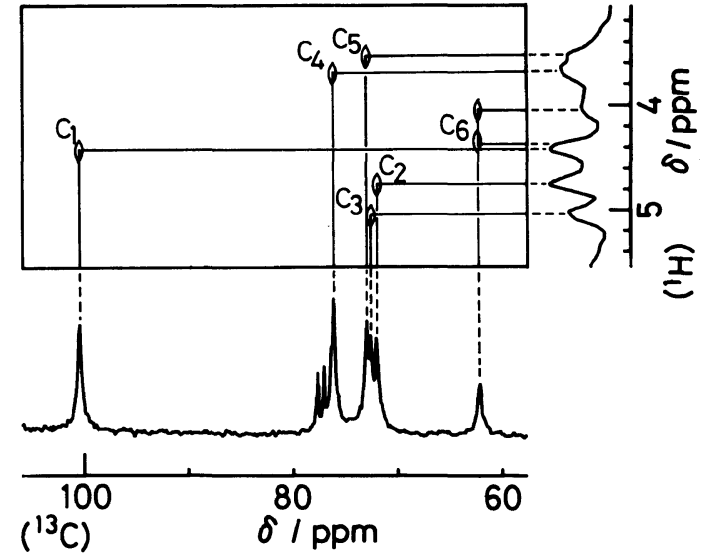

Figure 10. Schematic C-H COSY spectrum of CTA/ TCM- $d$ (glucopyranose region).

for the CTA/TCM- $d$ system. In the $1 \mathrm{D}-{ }^{13} \mathrm{C}$ spectrum (Figure 7(c)) a solvent (TCM-d) peak at $77 \mathrm{ppm}$ is extraordinarily large and overlaps some of the CTA peaks, making further analysis on CTA spectrum impossible. In contrast to this, in the 2D-spectrum, no peak of TCM$d$, in which $\mathrm{C}-\mathrm{H}$ coupling does not exist, is observed.

Figure 10 shows a schematic $\mathrm{C}-\mathrm{H}$ COSY 2D-spectrum constructed from Figure 9 and 


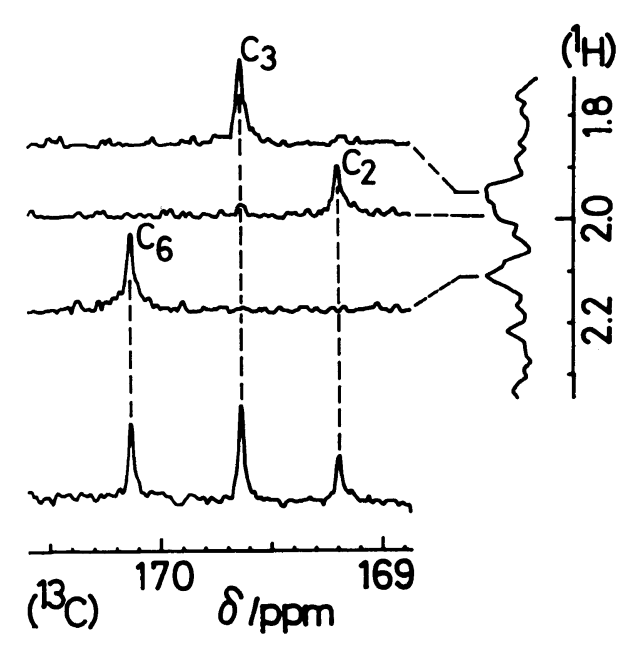

Figure 11. Cross-sections of long-range $\mathrm{C}-\mathrm{H}$ COSY spectrum of CTA/TCM-d (acetyl carbonyl carbon region).

its cross section for the CTA/TCM- $d$ system. In the figure, the projection of spectrum on the ${ }^{13} \mathrm{C}$ (horizontal) axis and the ${ }^{1} \mathrm{H}$ (longitudinal) axis are also shown. Carbon peaks can be assigned based on assignment of proton peaks, using the $\mathrm{C}-\mathrm{H}$ correlations shown in Figure 10 , from lower magnetic field, to $C_{1}, C_{4}, C_{3}$, $\mathrm{C}_{5}, \mathrm{C}_{2}$, and $\mathrm{C}_{6}$. However, here $\mathrm{C}_{3}$ and $\mathrm{C}_{5}$ overlap and are unseparable.

Figure 11 shows cross section spectra of long-range $\mathrm{C}-\mathrm{H}$ COSY spectrum between the acetyl methyl proton and the acetyl carbonyl carbon in CTA/TCM-d. Three correlation peaks in these figures are peaks, originating from long-range scalar coupling of the carbonyl carbon of acetyl group and acetyl methyl proton. If we denote carbonyl carbon peaks, from lower magnetic field, as a, b, and c, then the acetyl methyl proton peaks are assigned, using these correlation peaks, to a, c, and $b$. These relations are in an excellent agreement with the correlation, obtained by long-range selective spin decoupling method by Kowsaka et $a l .{ }^{6}$ Using these results, together with the assignment of the acetyl methyl proton peak chemically speculated by Goodlett et al., ${ }^{18}$ carbonyl carbon peaks can be assigned, from lower magnetic field, to $\mathrm{C}_{6}$, $\mathrm{C}_{3}$, and $\mathrm{C}_{2}$, respectively. It is also expected that if long-range scalar coupling between the glucopyranose skeleton proton and carbonyl carbon could be observed, carbonyl carbon peaks at $\mathrm{C}_{2}, \mathrm{C}_{3}$, and $\mathrm{C}_{6}$ positions could be ultimately. However, actually a possible longrange coupling constant between the proton attached to glucopyranose carbon and carbonyl carbon (i.e., $\mathrm{H}_{6}$ proton and carbonyl carbon at $\mathrm{C}_{6}$ position) is too small indeed to detect and in addition, in long-range $\mathrm{C}-\mathrm{H}$ COSY measurements, the $\mathrm{S} / \mathrm{N}$ ratio is significantly low due to the rapid transverse relaxation of magnetization of nuclei in CTA molecules. For this reason, we could not observe this kind of coupling for this polymer system. Similarly, we measured long-range COSY of protons in order to determine the correlation between the ring proton and the acetyl methyl proton, but failed due to the low $\mathrm{S} / \mathrm{N}$ ratio.

In the future, it may become possible to make a long-range measurement by (1) ${ }^{13} \mathrm{C}$ enrichment, (2) decrease in internal viscosity by lowering the polymer molecular weight, (3) 2D-NMR by high magnetic field NMR apparatus, and (4) using other advanced 2DNMR techniques such as correlation spectroscopy via long-range coupling (COLOC). ${ }^{17}$

From COSY and C-H COSY for the CTA/ DMSO- $d_{6}$ system, the almost comparable peak assignment, was obtained for the CTA/ DMSO- $d_{6}$ system in the same line of the discussion carried out for CTA/TCM- $d$. Figure 12 shows a stacked plot of long-range C-H COSY (carbonyl carbon peak region) for CTA/DMSO- $d_{6}$ system. From the figure, the correlation between carbonyl carbons and acetyl methyl protons, obtained by long-range selective spin decoupling method by Kowsaka et al., ${ }^{6}$ was again confirmed.

Summarizing, the reliability of peak assignment, hithetofor proposed, of ${ }^{1} \mathrm{H}$ and ${ }^{13} \mathrm{C}$ NMR spectra for cellulose and its triacetate was undoubtedly strengthened by use of 2D- 


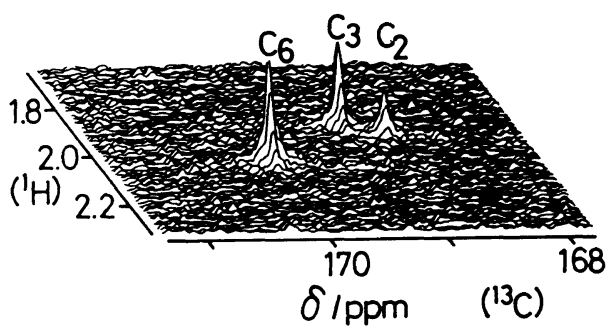

Figure 12. Stacked plot for long-range $\mathrm{C}-\mathrm{H}$ COSY spectrum of CTA/DMSO- $d_{6}$ (acetyl carbonyl carbon region).

NMR. It was demonstrated that overlapping peaks in 1D-NMR whose existence could only be speculated from their intensity, were experimentally verified often from the splitting of peaks on 2D-spectrum.

Now there seems to be the possibility of much further advance in reliable and complete assignment by using 2D-NMR, of almost all peaks in NMR spectra of not-fully substituted cellulose derivatives with $\langle\mathrm{F}\rangle$ ranging $0.5-$ 2.5 , for which peak assignment was unfortunately impossible by $1 \mathrm{D}$-spectrum alone due to coexistence of various kinds of glucopyranose units (that is, unsubstituted, mono-, di-, and trisubstituted units).

\section{REFERENCES}

1. K. Kamide, K. Okajima, T. Matsui, and S. Manabe, Polym. J., 12, 521 (1980).

2. D. Gagnaire, D. Mancier, and M. Vincendon, $J$. Polym. Sci., Polym. Chem. Ed., 18, 13 (1980).

3. K. Kamide, K. Okajima, T. Matsui, and $\mathrm{K}$. Kowsaka, Polym. J., 16, 857 (1984).

4. K. Kamide, K. Okajima, T. Matsui, M. Ohnishi, and H. Kobayashi, Polym. J., 15, 309 (1983).

5. K. Kamide and K. Okajima, Polym. J., 13, 127 (1981).

6. K. Kowsaka, K. Okajima, and K. Kamide, Polym. $J ., 18,843$ (1986).

7. K. Kamide, K. Okajima, K. Kowsaka, and T. Matsui, Polym. J., 19, 1405 (1987).

8. K. Kamide, K. Okajima, K. Kowsaka, T. Matsui, S Nomura, and K. Hikichi, Polym. J., 17, 909 (1985).

9. K. Kamide, K. Kowsaka, and K. Okajima, Polym. J., 19, 231 (1987).

10. K. Kamide, K. Okajima, and T. Matsui, Polym. J., 19, 347 (1987).

11. K. Kamide, K. Okajima, and K. Yasuda, unpublished results.

12. T-K. Wu, Macromolecules, 13, 74 (1980).

13. D. Clark and P. Stephenson, Polymer, 22, 1112 (1981).

14. T. Miyamoto, Y. Sato, T. Shibata, H. Inagaki, and M. Tanahashi, J. Polym. Sci., Polym. Chem. Ed., 22, 2363 (1984).

15. R. Narden and M. Vincendon, Macromolecules, 19, 2452 (1986).

16. W. Brown and R. Wikström, Eur. Polym. J., 1, 1 (1966).

17. For example, E. Breitmeier and W. Voelter, ${ }^{" 13} \mathrm{C}$ NMR Spectroscopy," 3rd Ed, Verlag Chemie, Weinheim, New York, 1986.

18. V. Goodlett, J. Dougherty, and H. Patton, J. Polym. Sci., A-1, 9, 155 (1977). 